\title{
Communicating curriculum reform to students: Advice in hindsight..... Michelle M McLean*1,2
}

Address: ${ }^{1}$ Department of Physiology, Nelson R. Mandela School of Medicine, University of Natal, South Africa and ${ }^{2}$ Faculty of Health Sciences, University of Natal, Durban, South Africa, 4001

Email: Michelle M McLean* - mcleanm@nu.ac.za

* Corresponding author

Published: 3 June 2003

BMC Medical Education 2003, 3:4
Received: 27 March 2003

Accepted: 3 June 2003

This article is available from: http://www.biomedcentral.com/1472-6920/3/4

(c) 2003 McLean; licensee BioMed Central Ltd. This is an Open Access article: verbatim copying and redistribution of this article are permitted in all media for any purpose, provided this notice is preserved along with the article's original URL.

\begin{abstract}
Backgound: In view of the changing health care needs of communities, curriculum reform of traditional curricula is inevitable. In order to allay the apprehension that may accompany such change, curriculum development and implementation should be an inclusive process, with both staff and students being well informed of the planned reform. In 200I, the Nelson R. Mandela School of Medicine implemented Year I of a problem-based learning curriculum. During the design phase, students and staff were invited to take part in the development and were kept abreast of developments through meetings and newsletters.
\end{abstract}

Method: A survey of Years I-5 students of the last intake into the traditional curriculum was undertaken a few months prior to the implementation of the new programme.

Results: Students were generally well informed about the impending change, having heard about it from fellow students and staff. The more senior the students, the less the perceived impact of the reform. Although most of what students had heard was correct, some, however, had misconceptions that were generally extreme views (e.g. all self-directed learning; no Anatomy) about the new programme. Others expressed valid concerns (e.g. underpreparedness of students from disadvantaged schools; overcrowding in hospitals).

Conclusions: Advice offered to institutions considering curriculum reform include using various methods to inform internal and external affected parties, ensuring that the student representative body and staff is well informed, reiterating the need for the change, confirming that the new programme meets recognised standards and that the students most affected are reassured about their future studies.

\section{Background}

Change is an inevitable part of society. While there will always be those welcoming it, viewing change as progressive and probably long overdue, there will be the opponents, who believe that there is nothing wrong with the old system. Curriculum restructuring and reform is no exception, with faculty staff and students either embracing or resisting the need to change. Reform often involves adopting a new philosophy. Those entrenched in the old system may find it difficult to adapt, particularly if their power and authority is challenged [1,2]. Students are probably no different from staff in the manner in which they accept the change. As the products of the restructuring process, however, they are directly affected by the 
reform, as they need to be 'marketable' in society, and in the case of medical training, they need to be educated to deliver an effective health care service. Implementing successful curriculum reform thus involves convincing both staff and students of the need for the innovation, which might involve highlighting shortcomings of the 'old'.

The 1993 World Summit on Medical Education, in evaluating the global need for a more effective health care delivery, provided the impetus for medical faculties to restructure their curricula. The WFME (1994) has advocated a redesigning of the $21^{\text {st }}$ century doctor in order to train practitioners to provide an efficient primary health care service, communicate better with patients, be critical thinkers and life-long learners, as well as work as members of a multidisciplinary team for the benefit of the community [3]. Reform of the traditional medical curriculum should therefore be inevitable in the light of these recommendations. Successful implementation of any reform, however, requires considerable planning, advertising and convincing of staff and students of the need for and the benefits of change [4-9]. Bland and co-workers (2000), in an extensive review of the literature, provide a detailed analysis of the characteristics necessary for successful curriculum reform [8]. Of interest to the present discussion is one of these features: communication regarding the reform. According to those authors, frequent, forthright communication and regular updates of progress with examples of proposed teaching practices are just some of the issues that need to be communicated to faculty in order to allow for objections to be aired, to invite participation and to establish and promote investment in the reform process [8]. It is critical that both staff and students be involved in this communication, as both parties will have reservations about innovations which might impact on their present and future careers $[5,8]$. Communicating widely and effectively, particularly if it is reciprocal, will ensure that faculty develops a sense of ownership in the reform process $[5,8,9]$, hopefully preventing or alleviating perceptions of loss of control.

Following more than 3 years of curriculum planning and development at the Nelson R. Mandela School of Medicine (Durban, South Africa), Curriculum 2001 was due to be implemented in January 2001. As a member of the Curriculum Development Task Force (CDTF) the author was interested in the awareness, perceptions and opinions of this proposed problem-based (PBL) curriculum amongst students in the traditional curriculum being phased out, a few months prior to the implementation of Year 1 of this curriculum (Curriculum 2001). Currently, following two years of curriculum implementation, and with the third year having just commenced, this discussion seeks to ascertain whether curriculum planners and developers succeeded in informing students about this new programme, and whether some of the issues raised by students have materialised. Canvassing traditional curriculum students' (Years 1-5) opinions of Curriculum 2001 and its perceived impact on their studies has provided Faculty with some insight into areas of concern that could be addressed. In terms of the frequently asked questions from staff and students two years after the initial implementation, lessons have been learnt and valuable advice can be offered about communicating reform, which might prove useful for other institutions considering curriculum restructuring.

\section{Methods}

The institution

The Nelson R. Mandela School of Medicine was established in 1950 to train Black (which historically included African, Indian and Coloureds) doctors. The situation persisted until a Faculty Board decision in 1996, in line with the new political dispensation in the country, was passed to adopt an open admission policy. Since 1996, the School has admitted students of all race groups, largely on academic criteria, but taking previous disadvantage into consideration. Students are therefore diverse in their educational and socio-economic backgrounds as well in their cultural and ethnic origins.

\section{The traditional curriculum and the need for reform}

The curriculum practised since 1950 has been a traditional, discipline-based one in which students undertook two years of preclinical training before limited patient contact late in the third year. Over the last few years, piecemeal changes were introduced into the MBChB programme, largely by departments as a result of limited resources and increasing student numbers (e.g. computeraided instruction in Histology and Pathology). The initial Faculty-directed reform took place in 1996, when the first year course was changed from a science-based (e.g. Physics, Chemistry, Biology) to a more medically relevant academic year (e.g. Community Health, Emergency Care Practitioner's course; Anatomy and Physiology). This reform was, however, insufficient as it did not address the recognised problems of later years of the programme (i.e. content overload; late exposure to patients) [10,11]. In line with the global trend towards PBL curricula with early exposure to clinical medicine, in which skills, attitudes, ethics and values become important in the training of competent medical practitioners [3], work began on identifying a programme that would improve health care delivery in South Africa in the light of issues such as HIV/ AIDS and poverty.

In July 1997, the Faculty Board adopted a proposal to replace the traditional, discipline-based 6-year curriculum with a 5-year PBL programme. The CDTF set about designing the blueprints and matrices for themes within the 
proposed programme, once the "core" components of each discipline had been identified.

\section{Communicating curriculum change}

During the planning and design phase of the Curriculum 2001 (1998-2000), numerous newsletters advertising the progress were distributed to students and staff in the Faculty, including the Medical Students' Representative Council (MSRC). Lunch-time question and answer sessions were organised, and students were addressed on several occasions by CDTF members, such as at the students' clinical conference and MSRC meetings. Various CDTF members addressed the media, while the librarians regularly posted updates on display boards at the entrance to the medical library. As the blueprint and matrix for each theme developed, Faculty members were invited to inspect and comment on the content and skills. Faculty Board, where students are represented, was appraised of the progress through the report of the Undergraduate Committee, which also has student representation.

\section{The present study}

With the implementation of Curriculum 2001 in January 2001, 2000 was the last year in which Year 1 of the traditional programme was offered. It was therefore decided to anonymously survey students undertaking Years 1-5 of this curriculum with regard to various aspects of their academic life to provide a baseline study against which to compare the new curriculum. $97.5 \%$ of questionnaires were recovered. In the aspect of the study currently being reported, as a member of the CDTF responsible for generating curriculum newsletters, and after three years of programme planning and communicating with Faculty, the author was interested in how informed students were with regard to the curriculum being implemented early the following year. Students were asked if they were aware of the impending PBL medical curriculum in the Faculty in January 2001, what they knew about this curriculum, and where or from whom had they heard about it. In addition, they were asked whether Curriculum 2001 would impact on their studies and what their opinions were of this new curriculum. Only simple descriptive statistics have been applied as the results are described largely from a qualitative perspective.

\section{Results}

Sources of information pertaining to Curriculum 200 I

Irrespective of the year of study, the majority of students $(95 \%)$ in the Faculty were aware of the implementation of the new curriculum (Table 1). Faculty sources (students and staff) were largely responsible for informing students of the proposed changes (Table 2). This included first year students who did not spend much time on the medical school campus. Over one-fifth of students identified lecturers as their source of information. These staff members were most likely to have gleaned information from reports submitted to Board meetings, facilitator training and from the Faculty newsletters published by curriculum developers.

In terms of notices and publications, the medical library notice board provided many students, particularly $4^{\text {th }}$ $(19.8 \%)$ and $5^{\text {th }}(16.1 \%)$ years, with information. This is encouraging, as it means that students do visit the library. Not a single $1^{\text {st }}$ year student identified the library notice board, which is understandable since most of their studies were conducted on the main university campus. In the wider university community, the University's Prospectus was the most successful publication in informing registered students, which would suggest that prospective students and their parents might also become informed through this medium (Table 2). In comparison with internal sources of information, external and other sources accounted for only a small proportion of students' sources (Table 3). Of these, the newspaper, which would have obtained information from curriculum developers, accounted for $5 \%$ of students' information.

Table I: Student awareness of the implementation of Curriculum 200I, and their perceptions of its impact (expressed a \% of students completing the item).

$\%$ students responding positively Year of study (number of students com-
pleting questionnaire)

First year $(n=187)$

Second year $(n=167)$

Third year $(n=193)$

Forth year $(n=132)$

Fifth year $(n=124)$

All students $(n=803)$

$95.0 \pm 1.45(n=792)$

Are you aware of the implementation of Curriculum 200I in January 200I?
Do you think you will be affected by the implementation of Curriculum 200I?

$\begin{array}{rr}95.5(n=178) & 52.0(n=174) \\ 95.2(n=166) & 34.2(n=157) \\ 92.8(n=193) & 21.1(n=188) \\ 94.7(n=131) & 25.2(n=120) \\ 96.8(n=124) & 20.5(n=117) \\ 95.0 \pm 1.45(n=792) & 30.6 \pm 13.2(n=746)\end{array}$


Table 2: The 5 most important Faculty and University sources of information pertaining to awareness of curriculum reform for each year group. $* \mathbf{8 2 . 1} \%$ of students (range: $68.4-97.7 \%$ ) had heard from Faculty sources and 4.7\% (range: $4.0-5.3 \%$ ) had heard from the University of Natal (NU) sources.

\begin{tabular}{|c|c|c|c|c|c|}
\hline \multirow[b]{2}{*}{$\begin{array}{l}\text { Year of } \\
\text { study }\end{array}$} & \multicolumn{5}{|c|}{ Ranking of source of information } \\
\hline & $\mathbf{I}$ & 2 & 3 & 4 & 5 \\
\hline $\begin{array}{l}\text { First } \\
(n=178)\end{array}$ & Students: $38.2 \%$ & Lecturers: $31.5 \%$ & Dean: $6.7 \%$ & Faculty admin: $4.8 \%$ & NU Prospectus: $4.5 \%$ \\
\hline $\begin{array}{l}\text { Second } \\
(n=166)\end{array}$ & Students: $31.3 \%$ & Lecturers: $24.7 \%$ & MSRC: $6.0 \%$ & NU Prospectus: $4.2 \%$ & $\begin{array}{l}\text { Med ical library } \\
\text { notice board: } 3.0 \% \\
\text { Medical School } \\
\text { campus: } 3.0 \%\end{array}$ \\
\hline $\begin{array}{l}\text { Third } \\
(n=193)\end{array}$ & Students: $24.4 \%$ & Lecturers: $17.1 \%$ & $\begin{array}{l}\text { Med library notice } \\
\text { board: } 9.8 \%\end{array}$ & MSRC: $4.1 \%$ & $\begin{array}{l}\text { Curriculum } \\
\text { organisers: } 3.6 \%\end{array}$ \\
\hline $\begin{array}{l}\text { Fourth } \\
(n=|3|)\end{array}$ & Students: $24.4 \%$ & Lecturers: $21.4 \%$ & $\begin{array}{l}\text { Med library notice } \\
\text { board: } 19.8 \%\end{array}$ & MSRC: $14.5 \%$ & $\begin{array}{l}\text { Curriculum } \\
\text { organisers: } 6.9 \%\end{array}$ \\
\hline $\begin{array}{l}\text { Fifth } \\
(n=124)\end{array}$ & Students: $18.6 \%$ & Library: $16.1 \%$ & Lecturers: $13.7 \%$ & MSRC: $10.5 \%$ & Tutors: $4.8 \%$ \\
\hline $\begin{array}{l}\text { All years } \\
(n=792)\end{array}$ & Students: $28.0 \%$ & Lecturers: $22.1 \%$ & Library: $8.8 \%$ & MSRC: $7.1 \%$ & NU Prospectus: $3.0 \%$ \\
\hline
\end{tabular}

\section{Details regarding Curriculum 2001}

Students were generally well informed about Curriculum 2001 , in the light of the details they provided (i.e. 5-year, self-directed learning (SDL), modular curriculum) (Table 4). Some comments suggest, however, that the SDL aspect might have been perceived as extreme in that some students believed that there would be no lectures or notes given. A few other misconceptions were expressed. The most common revolved ( $\pm 2 \%$ of students) around the issue of the absence of a Physics and Chemistry component. This misconception might have arisen because students were aware that the curriculum would address cases, real problems and clinical medicine from the outset on the medical campus, rather than in the Science Faculty on the main campus, where in Year 1 of the traditional curriculum, they had studied Chemistry, Physics and Biology (Table 4).

In response to the question "What have you heard about the curriculum?", a small proportion of students expressed either negative or positive perceptions and opinions of Curriculum 2001 (Table 5). Of the negative perceptions, the comment that the degree was not recognised internationally, was the most frequent (3.2\% of students). At the other extreme, there were comments regarding the beneficial effects of this curriculum, which included improving health care (which is the reason for local and global reform in medical education) in South Africa. A handful of students had heard from others that the curriculum was more student-friendly, exciting and easier, while others had heard that it would be more difficult and challenging (Table 5).

\section{Student perceptions of the impact of Curriculum $200 \mathrm{I}$ on their studies}

Since the statement in the questionnaire clearly asked about the impact of Curriculum 2001 on the individual student, one must assume that student comments refer to their perceived personal impact. The perceived impact of Curriculum 2001 generally decreased the more senior the students, with $52 \%$ of $1^{\text {st }}$ years and less than $21 \%$ of $5^{\text {th }}$ years indicating that the proposed curriculum would impact on them (Table 1). Table 6 summarises the two most frequently expressed views on the impact of the new programme on their studies. While some $1^{\text {st }}$ years $(16.5 \%)$ were aware that failure in Year 1 of the traditional curriculum might result in their incorporation into the PBL curriculum (which was true), others were unsure. Some believed that they would be excluded if they failed. Others were concerned about their fate in the event of failing later years (would they be excluded or would they have to join the new curriculum?). While the impact of failing was of concern to $1^{\text {st }}$ and $2^{\text {nd }}$ years $(35.2$ and $14.8 \%$, respectively), senior students $\left(53.3 \%\right.$ and $45.8 \%$ of $4^{\text {th }}$ and $5^{\text {th }}$ years, respectively) were more perturbed with overcrowding in the hospitals (where, in their opinion, there were already too many students). A shortage of other resources such as computers and library material was also seen as a possible problem with the implementation of the new programme (Table 6).

Some students believed that with Curriculum 2001, there would be more PBL in their traditional course, with others commenting that their course had already changed, with elements of PBL. Some students believed that they would 
Table 3: External and other sources of information for students regarding Curriculum 2001.

\begin{tabular}{|c|c|}
\hline Source & \% students $(n=792)$ \\
\hline Individuals outside the Faculty & 11.7 \\
\hline Friends* & 3.9 \\
\hline Family & 0.9 \\
\hline General public & 0.8 \\
\hline GP/family doctor & 0.6 \\
\hline Pupils at school & $<0.5$ \\
\hline Students at other universities & $<0.5$ \\
\hline External media & 8.3 \\
\hline Newspaper & 5.1 \\
\hline Media & 1.4 \\
\hline Internet & 1.0 \\
\hline TV & 0.8 \\
\hline Government news & $<0.5$ \\
\hline Other sources & 4.5 \\
\hline Grapevine/around & 4.2 \\
\hline Reliable source & $<0.5$ \\
\hline Various sources & $<0.5$ \\
\hline Non-specific responses & 2.3 \\
\hline Can't remember & 1.1 \\
\hline Read about it & 1.0 \\
\hline Saw it & $<0.5$ \\
\hline
\end{tabular}

* might include students

Table 4: Details of Curriculum 2001 provided by students in response to the question: "What have you heard about Curriculum 200 I?" Only the 12 most frequent details are provided from an extensive list.

\begin{tabular}{lc}
\hline $\begin{array}{l}\text { Details of the curriculum identified (with } \\
\checkmark \text { for correct information and } \mathbf{x} \text { for incor- } \\
\text { rect information) }\end{array}$ & $\begin{array}{c}\text { \% students } \\
(\boldsymbol{n}=\mathbf{7 9 2})\end{array}$ \\
\hline Five year/shorter curriculum $(\checkmark)$ & 29.3 \\
Modular $(\checkmark)$ & 27.0 \\
Self-directed $(\checkmark)$ & 13.0 \\
Decrease/no lectures $(\checkmark / \mathbf{x})$ & 10.5 \\
Clinical/patient contact from start $(\checkmark)$ & 10.1 \\
Integrated $(\checkmark)$ & 6.4 \\
Different from traditional curriculum $(\checkmark)$ & 4.4 \\
Like TB/CVS module $(\checkmark)$ & 3.9 \\
Tutorials/facilitator/small groups $(\checkmark)$ & 3.8 \\
Hands-on/practical/real problems $(\checkmark)$ & 3.4 \\
Case-based $(\checkmark)$ & 2.2 \\
No physics and chemistry/decrease in basic sci- \\
ence $(\mathbf{x} / \checkmark)$
\end{tabular}

Table 5: Student perceptions and opinions of Curriculum 200I: Student responses to the question: "What have you heard about Curriculum 200I?"

\begin{tabular}{lc}
\hline Perceptions and opinions & $\begin{array}{c}\text { All students } \\
(\boldsymbol{n}=\mathbf{7 9 2})\end{array}$ \\
\hline Value of education/degree - positive & 1.3 \\
Trains doctors to be an asset to SA/better & $\mathbf{0 . 6}$ \\
health care & \\
Same as what is happening internationally & 0.3 \\
Will benefit us & $<0.3$ \\
Improve the way Medicine is learnt & $<0.3$ \\
Improvement in clinical skills & $<0.3$ \\
Value of education/degree - negative & 3.9 \\
Not internationally recognised & 3.2 \\
Tried overseas and doesn't work & $\mathbf{0 . 4}$ \\
Lowers value of our degree/substandard & $\mathbf{0 . 3}$ \\
People say it will not work & $<0.3$
\end{tabular}

Relating to the programme - positive 2.5

Interesting/exciting $\quad 0.8$

Easier $\quad 0.4$

Less stressful/student-friendly $\quad 0.4$

Better than current $\quad 0.4$

Interactive $<0.3$

Dynamic $\quad<0.3$

Excellent idea $<0.3$

Better recall $<0.3$

More direct approach $\quad<0.3$

Relating to the programme - Negative 2.1

More difficult/challenging $\quad 0.9$

Relating to failing $\quad 0.5$

Not good/negative aspects $\quad 0.4$

More pressure on students $\quad<0.3$

Not interesting $\quad<0.3$

A lot of work $\quad<0.3$

Other comments $\quad 4.0$

Not much $\quad$ I.4

Details on how it works I.I

Lecturers will have less work to do $\quad 0.9$

Pros and cons $\quad 0.4$

Only for 200I students/won't affect us $\quad<0.3$

Students will finish with us $\quad<0.3$

be neglected as efforts of staff would be concentrated on the new curriculum. This was not unique to first years, with $10 \%$ of $3^{\text {rd }}$ years believing this would be the case (Table 6).

\section{Student opinions of Curriculum 200I}

In this open-ended section of the questionnaire, students provided a comprehensive list of opinions (positive and negative) with regard to the new curriculum (Tables 7 \&8). A large proportion of the comments could be summarised into four categories: should be implemented (e.g. excellent idea, about time), should not be implemented 
Table 6: Perceived impact of Curriculum 200I on students in a traditional curriculum: Student comments ( 2 most frequently expressed comments).

\begin{tabular}{lc}
\hline Comments & \% students* \\
\hline $\begin{array}{l}\text { First year } \\
\text { - Relating to failing }\end{array}$ & 35.2 \\
- Will increase PBL in our course, more stressful and & 4.4 \\
tedious & \\
Second year & 14.8 \\
- Relating to failing & 9.3 \\
- Increased number & \\
Third year & 15.0 \\
- Too many people and limited resources & 10.0 \\
- Students in the old curriculum will be neglected & \\
Fourth year & 53.3 \\
- Overcrowding & 13.3 \\
- Standards will drop & 45.8 \\
Fifth year & \\
- Overcrowding & \\
\hline
\end{tabular}

* Expressed as a percentage of students who indicated that the curriculum would impact on them (see Table I).

(e.g. bad idea), not sure and no opinion (Table 7). Based on these sentiments, more students were generally in favour of the new PBL curriculum (almost one-third of students). The positive attitude generally increased with student seniority. Understandably, $1^{\text {st }}$ years, who would be impacted most by the introduction of the curriculum, were the most sceptical (Table 7). Table 8 depicts the two most frequently expressed positive and negative comments for each year group (excluding the direct responses in Table 7). The positive responses generally revolved around the integrated nature and the early clinical exposure offered by the new curriculum. From a negative perspective, the main concern (largely the $3^{\text {rd }}-5^{\text {th }}$ year groups) was the maturity of those students arriving directly from school, where they have been 'spoon-fed', and their possible inability to cope with an SDL programme. A large proportion of the Faculty's intake is from historically disadvantaged groups.

\section{Discussion}

The results and sentiments expressed in this survey of almost 800 students, the last complete profile of the first 5 years of a traditional curriculum, prior to the implementation of a new PBL programme, would suggest that curriculum planners had generally been successful in informing students about the forthcoming curriculum. A range of sources of information was identified, with other students (35\%) being most frequently cited, followed by the Faculty staff. Word of mouth from within the institution thus appeared to be more important in this regard than any of the Faculty or University publications. The most successful written communication was the library notice board, but this was restricted to the students studying on the medical school campus. Such varied coverage would reinforce the belief that the use of multiple media increases the likelihood that information pertaining to the reform will be heard, and that repetition will reinforce the message [5].

External sources (media and general public) accounted for $\pm 20 \%$ of students' sources of information. Since a proportion of the students had 'heard' about the curriculum from sources outside the faculty, it is therefore equally important for curriculum planners to constantly update the external sources (through University publications and the media) regarding the progress. This is particularly important since the ultimate 'consumers' of the products of the reform will be the communities served by graduates of the reform.

Students had generally received the correct information regarding the new programme (i.e. small groups sessions, modular, early clinical exposure, etc.), although some had taken an extreme view of SDL (e.g. no notes or lectures). Since students had heard about the new programme from varied sources, it is inevitable that different opinions and perceptions will have been expressed by the sources, both within and outside the institution. As a result, some students may have received biased, subjective information, resulting in negative sentiments being expressed (e.g. not internationally recognised; lower standard). While it is not possible to accredit a curriculum that has yet to be implemented, it is imperative that curriculum planners provide students, staff and external interested parties with evidence for the need to change (e.g. Health Professions Council of South Africa (1999) recommendations for greater primary health care exposure)[12], which might involve highlighting the shortcomings of the old system. Credibility for the change would certainly be gained by advertising that the reform is in line with local and global recommendations and the worldwide trend in medical education reform (e.g. WFME, 1994)[3].

When given the opportunity to express their opinions, students were somewhat divided with respect to the forthcoming programme. Some viewed the new curriculum as a means of addressing difficulties experienced in the traditional programme (such as volume of work, delayed exposure to patients), which were some of the reasons for Faculty's decision to institute change. On the other hand, exposing $1^{\text {st }}$ year students to SDL from the outset, some believed, was not advisable since students entering the programme directly from school had been "spoon-fed" (in their words) and would not be able to adapt without support. There were several references to students from disadvantaged backgrounds not being able to cope, especially in terms of computer skills and the use of the library. 
Table 7: Student opinions of Curriculum 200I: General comments about implementation.

\begin{tabular}{|c|c|c|c|c|}
\hline \multirow[b]{2}{*}{ Year of study } & \multicolumn{4}{|c|}{$\%$ students* } \\
\hline & Should be implemented & $\begin{array}{l}\text { Should not be } \\
\text { implemented }\end{array}$ & Not sure & No opinion \\
\hline First $(n=187)$ & 21.4 & 18.7 & 12.3 & 2.7 \\
\hline Second $(n=167)$ & 26.9 & 13.2 & 3.6 & 6.0 \\
\hline Third $(n=193)$ & 27.5 & 7.8 & 5.7 & 10.4 \\
\hline Fourth $(n=132)$ & 25.8 & 12.9 & 9.1 & 2.3 \\
\hline Fifth $(n=124)$ & 44.4 & 15.3 & 2.4 & 7.2 \\
\hline All students $(n=803)$ & $29.2 \pm 8.8$ & $13.6 \pm 4.0$ & $6.6 \pm 4.1$ & $5.7 \pm 3.4$ \\
\hline
\end{tabular}

* Expressed as \% of students in that year.

Table 8: Student opinions of Curriculum 200I: Positive and negative comments. Only the 2 most frequently expressed comments for each group are reported. Comments in Table 7 have been excluded.

\begin{tabular}{|c|c|c|}
\hline \multirow[b]{2}{*}{ Year of study } & \multicolumn{2}{|c|}{$\%$ students } \\
\hline & Positive comments & Negative comments \\
\hline $\begin{array}{l}\text { First } \\
(n=187)\end{array}$ & $\begin{array}{l}\text { SDL will teach students responsibility: } \mathbf{2 . 7} \\
\text { Will lead to better doctors: I.I }\end{array}$ & $\begin{array}{l}\text { More difficult as students will have to do the work: } \mathbf{9 . 1} \\
\text { Will cause disadvantaged students to suffer: } \mathbf{3 . 7}\end{array}$ \\
\hline $\begin{array}{l}\text { Second } \\
(n=167)\end{array}$ & $\begin{array}{l}\text { Earlier patient access: } \mathbf{3 . 6} \\
\text { Integrated (skills and theory): } \mathbf{3 . 0}\end{array}$ & $\begin{array}{l}\text { Comfortable with the old system: } \mathbf{5 . 4} \\
\text { Will result in doctors trained for SA only: } \mathbf{3 . 0}\end{array}$ \\
\hline $\begin{array}{l}\text { Third } \\
(n=193)\end{array}$ & $\begin{array}{l}\text { Interesting: } \mathbf{6 . 1} \\
\text { Early clinical exposure: } \mathbf{3 . 6}\end{array}$ & $\begin{array}{l}\text { First years might not cope: } \mathbf{3 . 6} \\
\text { Big adjustment: } \mathbf{3 . 1}\end{array}$ \\
\hline $\begin{array}{l}\text { Fourth } \\
(n=132)\end{array}$ & $\begin{array}{l}\text { Integrated: } \mathbf{2 . 3} \\
\text { Allows students to learn better: } \mathbf{2 . 3}\end{array}$ & $\begin{array}{l}\text { Difficult for students straight from school: } \mathbf{9 . 1} \\
\text { Students from Bantu schools will be disadvantaged: } 4.5\end{array}$ \\
\hline $\begin{array}{l}\text { Fifth } \\
(n=124)\end{array}$ & $\begin{array}{l}\text { Better understanding: I.6 } \\
\text { Confident, responsible, well-rounded students: } \mathbf{1 . 6}\end{array}$ & $\begin{array}{l}\text { Students from school will not cope: } \mathbf{I} \mathbf{2 . 1} \\
\text { Students will need to be motivated: } \mathbf{4 . 0}\end{array}$ \\
\hline
\end{tabular}

These were indeed valid concerns on the part of the students, of which the CDTF was aware and which have been addressed in Curriculum 2001 (e.g. implementation of computing skills, English skills training, an orientation to PBL, etc.).

Like students at most institutions, those at the Nelson R. Mandela School of Medicine vociferously voice their concerns, objections and give their approval/disapproval to Faculty decisions relating to issues that might impact on their studies or their practice of medicine. The results of this survey demonstrate that the student population is an important force for disseminating information to other students, either as individuals or as part of the student representative body. The support given by the student body to curriculum reform should therefore not be underestimated and may be sufficiently powerful to influence the success of the proposed reform. What was not anticipated by curriculum planners, however, was the change in the student representative body early in the 2001 academic year following elections. Unfortunately, the time invested with the 2000 student representatives in the form of meetings and workshops could not be repeated with the incoming group of representatives, resulting in a less informed group of student representatives half way through 2001. From time to time, therefore, students approached the curriculum organisers when they could not resolve queries from students. In this regard, the issue of assessment (progress examinations, formative assessment and the objective structured clinical examinations) was particularly troublesome for both staff and students. For the 2002 academic year (second year of implementation), the orientation for incoming $1^{\text {st }}$ years was extended to three weeks, in which, apart from an in-depth introduction to the problem-based learning philosophy, the most common queries that arose during 2001 were formally addressed. A thorough evaluation conducted at the end of the 2002 orientation suggested that the message was received early in the academic year by the majority of students in the new curriculum. The student representative council was intimately involved in the orientation process. As the year co-ordinator for the first year of its imple- 
mentation, the author has had first hand experience of the major issues that faced the first two cohorts of students in Curriculum 2001 and has therefore been able to provide input into the design of the orientation. In 2002, Curriculum 2001 students were well presented on the MSRC and attended most meetings relating to curriculum implementation, which has contributed to a good staff/student relationship.

In a similar vein as with students, a well-informed staff will also be able to provide answers to student queries regarding various aspects of any change to be implemented or that has already taken place. While the results might indicate that staff members were important in communicating curriculum reform issues to students, in retrospect, two year later, it has become clear that many are still unsure of some aspects of the programme. These were largely those teachers in the senior years who have not undergone facilitator training, or who had not become involved in practicals, clinical skills or large group resource sessions in the new programme. Some may indeed be Faculty members who still oppose the reform. Curriculum organisers and planners therefore need to ensure all staff and students have been part of the negotiations and planning and are kept informed of the progress, in order to ensure their full support.

The majority of students completing this questionnaire were of the opinion that they would not be affected directly by the implementation of the new programme, save the $1^{\text {st }}$ years as the last intake in the traditional curriculum. Understandably, the $1^{\text {st }}$ year students, perceiving that the new programme would impact on their studies, had queries, which could not be or were not answered by curriculum organisers. To this end, there was some consternation at the end of 2000 regarding the fate of those in the traditional curriculum who failed in the $1^{\text {st }}$ or subsequent years of Curriculum 2001. While this issue had been debated at length at various Board and Undergraduate Committee meetings for more than a year preceding implementation, Faculty had generally been tardy deciding on and finally publicising the decisions, resulting in the uncertainty expressed in some student responses. The lesson to be learnt is that administrative issues in faculties and universities generally take longer than anticipated. Once matters such as rule changes and credit points have been discussed and agreed upon within the faculty, they need to be ratified by one or more university committees, all of which may take more than a year. In fairness to students (both those studying in the traditional curriculum and the prospective students inquiring about the programme being offered), it is important that such matters be settled and advertised at least a year prior to implementation. Particular attention needs to be given to those students most likely to be affected by the impend- ing change (the $1^{\text {st }}$ years in this instance, who might fail in the traditional programme).

The single most important negative perception $(3 \%$ of students) with regard to the new programme, and which persisted into the second year of implementation, was that the programme would not be recognised internationally (Table 5). It would appear that senior students in the old curriculum as well as some Faculty and provincial hospital staff might be responsible for fostering this idea. Linked to this, is the fact that new curriculum students have also been told (and correctly so) that their degree trains them to be general practitioners in South Africa. Students have interpreted this as implying that they are unable to practice elsewhere or specialise. As Year 1 coordinator for two successive years, the author has had to address such issues at the fortnightly meetings with the student representatives. Although various curriculum developers have attempted to address this matter, the author has resorted to providing students with a copy of the HPCSA (1999) guidelines for undergraduate medical education and training in South Africa [12] and the web site for the UK's General Medical Council. The latter was an attempt to make students aware of the need for the curriculum content to be relevant for local conditions. Students were also informed of the need to write lisencing examinations if they chose, after their internship and community service, to emigrate. From having experienced these concerns first hand, the advice that can be offered would be to provide students (both incoming and old curriculum) and staff (Faculty and health services) with repeated exposure to the need for curriculum reform, as well as the guidelines (local and international) followed in designing the curriculum. Negative perceptions should not be allowed to be voiced as they erode into the confidence that curriculum planners try to develop within and external to the institution prior to the implementation of the reform. During 2001, members of the HPCSA visited the Nelson R. Mandela School of Medicine to accredit the traditional curriculum. In an effort to dispel some of these negative perceptions regarding the new curriculum, the accreditation committee spent a considerable portion of their time discussing Curriculum 2001 with the curriculum developers. In its recently released report on the School, the traditional curriculum has been accredited, with some suggestions to increase the level of clinical exposure. Also in the report, were positive comments pertaining to the new curriculum, which address some of the shortcomings of the programme being phased out. The Faculty will continue to provide reports to the HPCSA regarding the phased implementation of Curriculum 2001. Details of the new programme were also communicated to the General Medical Council in 2000. 


\section{Concluding comments}

While curriculum planners were generally successful in communicating the proposed reform to students, it is clear that some issues may have been overlooked or not addressed adequately (e.g. assessment), which, in retrospect, would have been valuable to both students and staff and might have obviated some of the concerns during the first year of implementation. Undoubtedly, constant and continued communication, even if repetitive, must be the advice that can be offered to those planning curriculum reform. This communication should not, however, be restricted to the planning stages. Implementation involves organisers delivering the promised curriculum, and the subsequent evaluation (largely by students, since they experience the curriculum first hand) will justify the reform programme selected and quell the insecurities and objections with respect to the change. Since Curriculum 2001 was implemented in January 2001, it is only in its embryonic stages, a considerable onus therefore rests with curriculum organisers to continue providing feedback to staff and students about evaluation of each theme (content, cases, skills, organisation, etc.) and the course as a whole. As each 6-week theme has been evaluated by students and facilitators, the comments have been discussed with theme co-ordinators, often with students in attendance. Student results of examinations are communicated to the Faculty Board, through the Undergraduate Committee report, with students serving on both committees. Implementation itself provided curriculum organisers with insight into dealing with the second intake of Year 1 students and with subsequent years of study. Results of a survey with regard to communication between organisers and students (e.g. via WebCT, group representative meetings with the year co-ordinator, facilitators in small group sessions, etc.), indicates that the majority of students in Curriculum 2001 were satisfied that they received adequate and regular information.

Change is not easily accepted, especially when the "old" is believed to be adequate and has been in place for the last 50 years. The traditional medical programme at the Nelson R. Mandela School of Medicine is viewed by most Faculty staff (and probably the students) as having produced graduates who have become successful professional, politicians, administrators, specialists and researchers, both locally and internationally. Considerable convincing of Faculty was therefore necessary in order to ensure successful planning of a new programme. Dannefer and co-workers (1998), reporting on the collective experience of eight American medical schools undergoing funded curriculum reform, are of the opinion that communication is "a central and decisive element" in the successful implementation of change [5]. Amongst the factors that need to be communicated to all interested and affected parties is the need for change (e.g. a new type of graduate required or identifying flaws in the old programme), providing a feasible alternative, based on evidence collected, how change will impact faculty and how this change will be evaluated. Thus, from these data for the planning stages of Curriculum 2001, the message of what programme (including details) would be implemented, had generally been successful, based on the responses of students. Notwithstanding, from a few student comments, however, it would appear that the curriculum organisers had not been able to convey the full story. The few misconceptions that students expressed might be those that students had gleaned from less informed individuals (e.g. 'around'; 'the grapevine'; the general public, etc.). When students were given the opportunity to express their opinions of Curriculum 2001, the criticism voiced was generally not about the principles of PBL or SDL per se, but about the under-preparedness of some students (and legitimately so), based on their less than adequate educational background $[13,14]$, and the perceived lack of resources (e.g. computers, patients) in the Faculty and the provincial health care facilities.

Having now experienced and been intimately involved in two years of curriculum implementation, it is imperative that students and staff to be made aware from the outset, of the dynamic nature of the programme. For the majority of students, their parents and most staff, the PBL innovation is in itself is a difficult concept to accept. Any modification to an already new system has repercussions. Although organisers implement the curriculum to the best of their ability, there will always be (and should always be) modifications in response to evaluation. Such a situation arose with adjustments that had to be made to the manner in which the results of the progress examinations were calculated. Learning to manage the change is probably more of a challenge for students and staff than accepting the change itself.

The first intake of students into any innovative programme will always be the pioneers, shouldering the responsibility of treading unexplored territory and having to evaluate every aspect of the new programme. In order for a sustainable understanding to be fostered with these students, curriculum organisers need to be sensitive to their insecurities, fears and requests.

Perhaps more important than any report from curriculum organisers to faculty and external parties with regard to the progress, is the response of students to the new programme. While we have been able to gauge the general positive response of the $1^{\text {st }}$ year students through questionnaires, curriculum organisers have been fortunate that the first cohort of students (perhaps as a result of their personal development (a desired outcome) during the PBL programme) has been extremely vocal about expressing 
their acceptance or concerns of certain aspects of the programme. This has undoubtedly contributed to a mindset change amongst some of the sceptics, particularly since a number of these students are those who were incorporated into the new programme after failing in the traditional curriculum. Notwithstanding the overall success of the first two years of implementation, the work of the CDTF has, however, only just begun, as it will only be in 2005 that the entire new programme will become institutionalised. It is probably only at this point that the curriculum can be legitimised in the eyes of the students and all other parties with a vested interest in their education. Many challenges still lie ahead for curriculum organisers, including one pointed out by students completing this survey: 2 cohorts (new and traditional) of students graduating in 2005.

The final advice to be offered would be to evaluate staff and student perceptions of the forthcoming curriculum reform at least 6 months in advance of the first implementation. Assuming also that the design phase has been a consultative one, the major issues arising could be identified and addressed prior to implementation, thereby preventing them from haunting the new programme. From Mennin and co-workers' (1998) experience of curriculum reform, "addressing rumours and misinformation promptly was an essential communication process during the early phases of innovation" (p. 562)[6].

\section{Competing interests}

None declared.

\section{Acknowledgements}

The author would like to thank the students for responding so enthusiastically to the survey, and to Jacky van Wyk for assistance with the distribution and collection of the questionnaires.

\section{References}

I. Gale R and Grant J: AMEE Medical Education Guide No. I0: Managing change in a medical context: guidelines for action Med Teacher 1997, 19:239-249.

2. McLean M: Rewarding teaching excellence. Can we measure teaching 'excellence'? Who should be the judge? Med Teacher 200I, 23:6-II.

3. World Federation for Medical Education World Summit on Medical Education: The Changing Medical Profession. Recommendations Med Educ 1994, 28(Suppl I): 140- I49.

4. Bloom SW: The medical school as a social organisation: the source of resistance to change Med Educ 1989, 23:228-24I.

5. Dannefer EF, Johnston MA and Krackov SK: Communication and the process of educational change Acad Med 1998, 73:SI6-S23.

6. Mennin S and Krackov SK: Reflections on relevance, resistance, and reform in medical education Acad Med 1998, 73:S60-S64.

7. Gerrity MS and Mahaffy J: Evaluating change in medical school curricula: how did we know where we were going? Acad Med 1998, 73:S55-S59.

8. Bland CJ, Starnaman S, Wersal L, Moorhead-Rosenberg L, Zonia S and Henry R: Curricular change in medical schools: how to succeed Acad Med 2000, 75:575-594.

9. Bernier GM, Adler S, Kanter S and Meyer MJ: On changing curricula: lessons learned at two dissimilar medical schools Acad Med 2000, 75:595-60I.
10. Olmesdahl PJ: The establishment of student needs: an important internal factor affecting course outcome Med Teacher 1999, 21:174-179.

II. McLean M: Student perceptions of their first and second year experiences of medical studies at the University of Natal MEd Thesis. University of Natal, Durban, South Africa 2000.

12. Health Professions Council of South Africa: Education and Training of Doctors in South Africa. Undergraduate Medical Education and Training. Guidelines by the Medical and Dental Professional Board Pretoria, Medical and Dental Professional Board 1999.

13. Bezuidenhout DI: The Dialectic between Learning and Teaching at the University of Natal Medical School Masters Thesis, University of Natal, Durban, South Africa 1990.

14. Colborn RP: Affirmative action and academic support: African medical students at the University of Cape Town Med Educ 1995, 29:110-118.

\section{Pre-publication history}

The pre-publication history for this paper can be accessed here:

http://www.biomedcentral.com/1472-6920/3/4/prepub

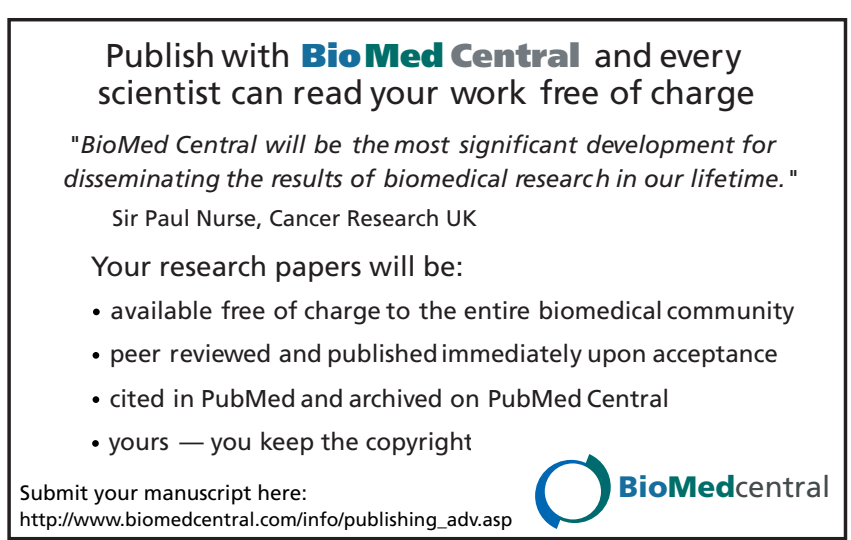

